\title{
脱附性医用高频电刀的研究现状及发展趋势*
}

\author{
陆龙生 ${ }^{1,2}$ 李凯凯 ${ }^{1,2}$ 谢颖熙 ${ }^{1,2}$ 万珍平 ${ }^{1,2}$ 丁焕文 ${ }^{3}$ 张志辉 ${ }^{4}$ 汤 勇 ${ }^{1,2}$
}

(1. 华南理工大学机械与汽车工程学院 广州 510640;

2. 广东省功能结构与器件智能制造工程实验室 广州 510640;

3. 广州市第一人民医院 广州 510180;

4. 吉林大学工程仿生教育部重点实验室 长春 130022)

摘要: 医用高频电刀通过刀头尖端电弧放电并产生热量完成组织的切割和止血工作, 是外科手术中的重要工具。在手术过程 中, 高频电刀温度过高会使血液和软组织脱水结痂甚至炭化, 粘连并包覆刀头, 进而对手术过程和医疗效果产生严重影响。 为能够有效解决医用高频电刀表面的生物组织粘连问题, 国内外诸多学者开展了电刀表面的脱附性研究, 具有明显疏血、散 热降温、抗组织粘附等效果的仿生脱附性医用高频电刀已成为该领域的研究热点和重要发展方向。按照现有脱附性医用高频 电刀的结构特点进行归纳分类并详细介绍其研究和应用现状, 着重介绍和分析仿生高频电刀的动植物脱附模型, 总结国内外 关于高频电刀表面脱附结构或涂层的制造方法, 分析讨论目前脱附性医用高频电刀所存在的问题, 最后对其未来的发展趋势 进行展望。

关键词: 医用高频电刀; 脱附性能; 仿生模型; 制造方法

中图分类号: TH777

\section{Research Status and Development Trend of Desorption Surgical Electromes}

\author{
LU Longsheng ${ }^{1,2}$ LI Kaikai $^{1,2} \quad$ XIE Yingxi $^{1,2}$ WAN Zhenping ${ }^{1,2}$ \\ DING Huanwen ${ }^{3}$ ZHANG Zhihui ${ }^{4}$ TANG Yong ${ }^{1,2}$
}

(1. School of Mechanical and Automotive Engineering, South China University of Technology, Guangzhou 510640;

2. Intelligent Manufacturing Engineering Laboratory of Functional Structure and Devices in Guangdong Province, Guangzhou 510640;

3. Guangzhou First People's Hospital, Guangzhou 510180;

4. The Key Laboratory of Bionic Engineering, Ministry of Education, Jilin University, Changchun 130022)

\begin{abstract}
As an important tool in surgical operation, surgical electromes are used to perform tissue cutting and hemostasis by discharging arc at the tip of the electromes and generating heat. In the process of surgery, over-high temperature of electromes make the blood and soft tissue dehydrate to form a scab even carbonize. Therefore, the electromes' head are adhered and covered, making a serious impact on the surgical process and medical effects. In order to effectively solve these problems, many scholars at home and abroad carry out studies on the surface adhesion of electrotomes. Some bionic desorption surgical electrotomes with obvious effects of anti-blood, thermolysis, anti-tissue-adhesivity and so on become a research hotspot and an important development direction in this field. The existing desorption electrotomes are classified according to the structural characteristics, and its research and application status are introduced in detail. Then the animal and plant desorption models of bionic electromes are emphatically introduced and analyzed, as well as the manufacturing methods of desorption microstructures on electromes' surface are summarized. Furthermore, the problems on exist the current desorption electromes are analyzed and discussed, and it is also proposed that more endeavors should be attempted to what in the future.
\end{abstract}

Key words: surgical electromes; desorption performance; bionic model; manufacturing method

\footnotetext{
* 国家自然科学基金 (51775197, U1601203)和广东省自然科学基金 (2019A1515011530) 资助项目。20190304 收到初稿, 20190726 收到修 改稿
} 


\section{0 前言}

据记载, 人类历史上最早进行医用的刀具可追 溯到公元前约 8000 年的中石器时代 ${ }^{[1]}$ 。随着人类文 明和医疗科技的重大进步，医用型刀具已成为医疗 领域内不可或缺的工具, 其相关行业发展势头迅猛。 现如今, 医用刀具种类繁多, 功能多样, 具体可分 为普通手术刀、高频电刀(单极和双极)、等离子刀、 氩气刀、超声刀、激光刀、 $\gamma$ 刀等 ${ }^{[2-3]}$, 广泛应用于 多种医疗手术场合。

医用高频电刀，又称高频电外科手术电极、电 凝等, 通过电流的热效应完成对肌体的切割和止血 工作, 以组织切割面整齐、渗血少、速度快、术后 疼痛少等优势著称 ${ }^{[3]}$ 。然而相关资料表明, 高频电 刀在手术过程中温度过高易造成血液和软组织脱水 结痂甚至炭化, 粘连并包覆刀头, 从而降低电流密 度, 阻碍能量传递, 进而影响手术切割效率和术中 止血效果; 倘若表面结痂与相邻组织发生粘连, 操 作过程中极易造成组织二次撕裂和出血, 使得伤口 愈合不良; 此外, 高频电刀产生的高温会通过热扩 散对周围组织或器官造成热损伤甚至坏死, 增加患 者的细菌感染概率 ${ }^{[3-5]}$ 。

为避免高频电刀造成上述不良后果, 手术过程 中医生往往会频繁地用医用纱布对电刀表面的血. 膜或结痂进行清理, 平均每隔 5 10 min 便会清理 一次, 使得手术时间严重延长。为降低电刀刀头的 温度和清除粘附物, 手术中也常用生理盐水对刀头 进行冲洗, 但该方法会阻挡外科医生视野, 且降低 电流密度, 直接影响手术效果 ${ }^{[6]}$ 。此外, 非电解质 类冲洗液还会导致溶血和低钠血症 ${ }^{[7]}$, 增加了手术 风险。

因此, 为了适应现代外科手术的严格要求, 必 须解决医用高频电刀表面的组织粘附问题, 研究开 发出脱附性强, 散热性好的医用高频电刀。近年来, 国内外诸多学者从不同方向对脱附性医用高频电刀 进行研究, 取得了较好的疏血、抗粘附、耐腐蚀及 散热良好等效果。然而到目前为止, 还没有关于脱 附性医用高频电刀领域的应用和发展综述。按照结 构特点对当前脱附性医用高频电刀进行归纳分类, 介绍和分析其研究与应用现状, 并结合自然界中具 有脱附功能的动植物表面重点介绍了仿生高频电刀 的脱附原理, 总结了目前国内外关于脱附结构或涂 层的主要制造方法, 最后讨论了当前脱附性高频电 刀存在的问题, 并进行科学的预测及展望, 为后续 脱附性医用高频电刀的研究提供借鉴与指导。

\section{1 脱附性医用高频电刀研究现状}

医用高频电刀一般由不锈钢、钛合金等金属材 料制成, 在湿润环境下其表面会吸附大量差基基团, 表面能较高, 展现出亲水性。在手术过程中, 高频 电刀不可避免的会与患者的血液、软组织等接触, 由于附着力 ${ }^{[8]}$ 的作用, 血液夹杂软组织会在电刀表 面形成血膜, 并在高温作用下逐渐脱水形成结痂甚 至炭化, 粘附更牢。2017 年, 西南交通大学 ZHENG 等 ${ }^{[9]}$ 最新研究发现, 高频电刀表面组织结痂炭化并 非只是受高温影响的结果, 而是热电耦合(温度场和 电场)作用的结果。图 1 所示为手术过程中高频电刀 表面产生的结痂现象。因而手术过程中须时常清理 刀具表面, 给手术过程带来了极大困扰。医用高频 电刀的脱附性研究, 是解决生物组织粘连的有效手 段, 同时也是其发展的必然趋势。目前, 按照脱附 性高频电刀的结构特点可将其分为辅助装置型, 涂 层型, 微结构型及复合型等。

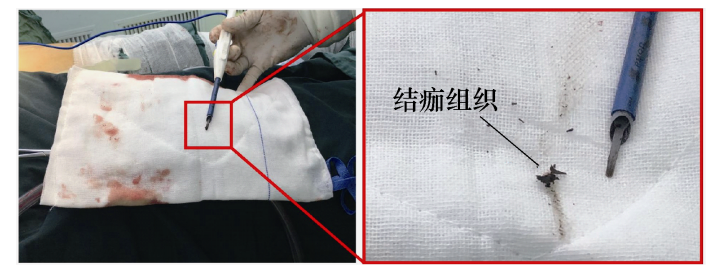

图 1 手术过程中高频电刀表面结痂现象

\section{1 辅助装置型}

2012 年, 美国密歇根大学 DODDE 等 ${ }^{[6]}$ 提出了 一种新型热管理系统(Thermal management system, TMS), 用于控制手术过程中单极电凝的温度。该系 统由高频电刀、冷却管道、固定支架及热敏电阻等 组成, 如图 2 所示 ${ }^{[6]}$ 。通过牛肝脏体外试验和有限 元仿真结果对比, 该系统能够有效控制单极电凝的 横向热扩散, 将温度控制在已知组织热损伤温度之 下，可减少刀头对周围组织的过热损伤。

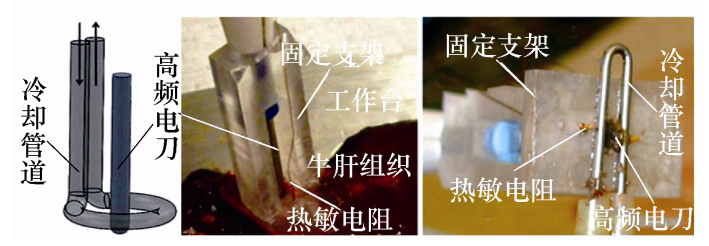

图 2 单极电凝热管理系统

2014 年, 郑建都发明了一种不粘电刀, 如图 3 所示 ${ }^{[10]}$ 。他在高频电刀内部设置了输送管, 将预冷 后的冷却剂(水或空气)直接输送至刀头, 并形成冷 却回路, 从而给电刀刀头降温。此外, 该电刀头由 
传热性好的铜或银制成, 并在表面涂覆了导电不粘 涂层。该发明可使电刀刀头表面温度保持在 $80{ }^{\circ} \mathrm{C}$ 以下, 从而防止刀头温度过高而粘附生物组织, 达 到防粘效果。

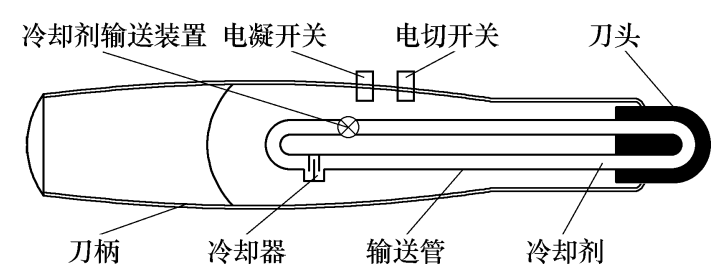

图 3 一种内部冷却回流型不粘电刀

2018 年, 北京航空航天大学 YAO 等 ${ }^{[11]}$ 自主设 计了一种超声振动辅助装置(UV-A), 将其与高频手 术电极机械联接, 如图 4a、4b 所示。手术电极由 电外科电路经后圆筒供电, 压电片由超声波电路供 电, 橡胶片用于绝缘隔离电外科电路和超声波电 路, 以避免电气干扰。手术电极的纵向振动由两个 相反极化的压电片激发, 可通过调节手术电极长 度, 将振动频率控制在 $42 \mathrm{kHz}$ 左右。将 UV-A 手 术电极进行鸡胸脯肉组织试切试验, 组织粘附力相 较于无 UV-A 的普通电极减少约 $60 \%$, 粘附质量减 少约 70\%, 热损伤区域面积减少 1.625 倍, 如图 4c、 $4 \mathrm{~d}$ 所示。试验表明, 超声振动辅助手术电极在提 高抗组织粘附性能和减少热损伤面积等方面具有 显著效果。
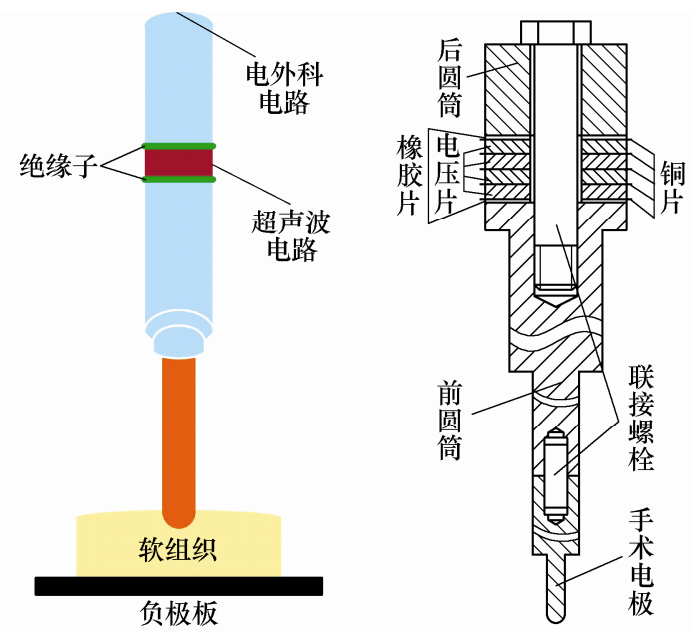

(a) UV-A 电外科电极单元示意图 (b) UV-A 电外科电极单元截面图

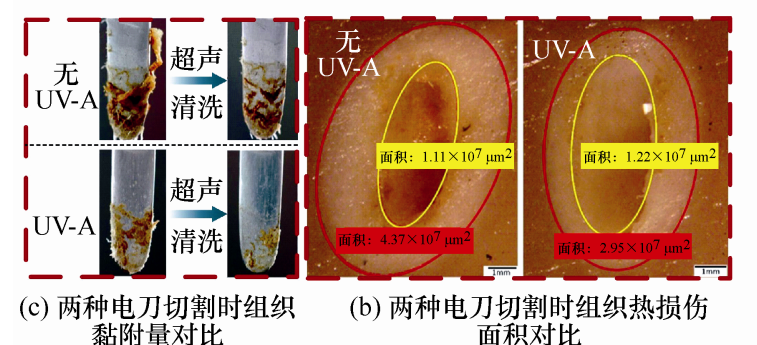

图 4 附加超声振动装置(UV-A)的高频手术电极

2018 年, 李明守等 ${ }^{[12]}$ 发明了一种内置加热单元
的手术刀, 并在刀具表面加工了由凸起部或凹陷部 呈周期性排列的微米级防粘连结构, 可减少人体组 织与刀片表面的接触面积, 使得该手术刀不仅具有 热凝血功能, 而且可有效避免组织粘连现象, 提高 了手术的安全性。

\section{2 涂层型}

针对微创手术中现有高频电外科手术器械易产 生手术烟、组织粘附和热损伤等问题, 研究人员在 高频手术器械表面通过引入抗粘性涂层进行脱附性 研究。

2010 年, 台湾成功大学 HSU 等 ${ }^{[13]}$ 在 SUS304 不 锈钢电刀表面分别沉积了 $\mathrm{CrWN}_{x}, \mathrm{CrO}_{x}$ 和 $\mathrm{ZrO}_{x}$ 三种 类型涂层。通过对比三种类型的涂层电刀, 发现 $\mathrm{CrO}_{x}$ 涂层具有 $33.5 \mathrm{mN} / \mathrm{m}$ 的最低表面能和 $103^{\circ}$ 的最高水 接触角。与普通 SUS304 不锈钢电刀相比, $\mathrm{CrWN}_{x}$ 和 $\mathrm{ZrO}_{x}$ 涂层电刀能够减少约 2 倍生物组织粘附量, $\mathrm{CrO}_{x}$ 涂层电刀可减少约 4.88 倍生物组织粘附量。普 通不锈钢与三种涂层型电刀的表面能、水接触角以 及组织粘附质量比情况如图 5 所示 ${ }^{[13]}$ 。

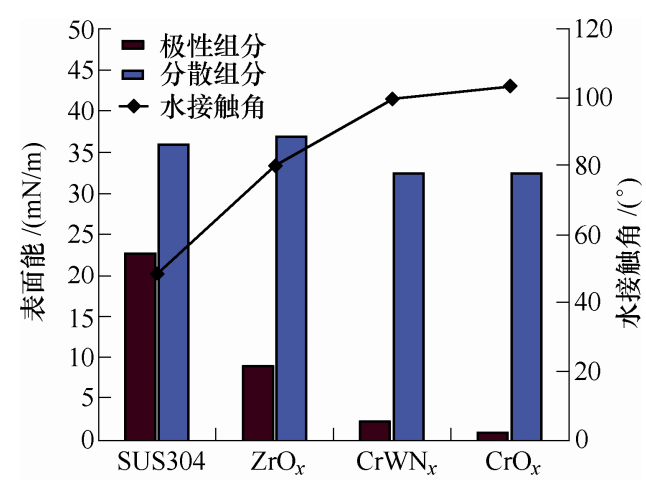

(a) 涂层型电刀与普通电刀表面能、接触角

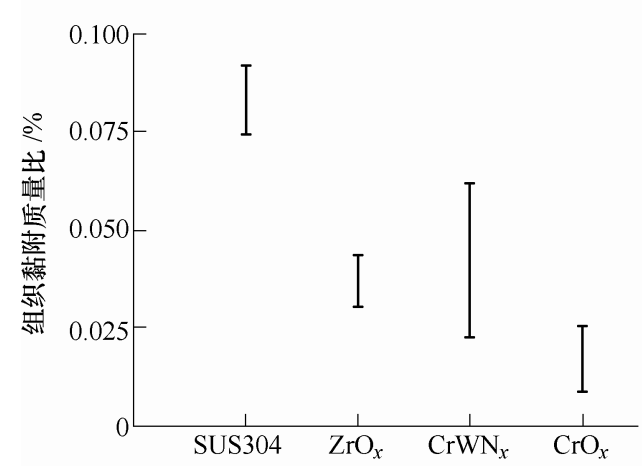

(b) 涂层型电刀与普通电刀手术切割试验 组织楾附质量比

图 5 三种涂层型电刀与普通电刀性能对比

2014 年, 台北医学大学 $\mathrm{OU}$ 等 ${ }^{[14]}$ 在电外科手术 针表面沉积一层厚度约 $1 \mu \mathrm{m}$ 炭黑色氮化铬 $(\mathrm{CrN})$ 薄 膜, 如图 6 所示 ${ }^{[14]}$ 。分别利用镀膜与普通电手术针 对成年大鼠肝叶进行切割试验, $\mathrm{CrN}$ 膜针较普通针 温度降低 $40{ }^{\circ} \mathrm{C}$ 左右, 过程中无烟雾产生, 表面组 
织粘附质量为 $(1.25 \pm 0.23) \mathrm{mg}$, 相较于普通针粘附质 量(3.76 0.52$) \mathrm{mg}$ 明显降低。2015-2016 年, 该团 队 ${ }^{[15-17]}$ 还在高频电刀表面结合了一层氢化含铜类金 刚石膜(DLC-Cu), 通过对比试验发现, 镀膜电刀能 够有效降低血红细胞和纤维蛋白的粘附量, 如图 7 所示 ${ }^{[15]}$ 。此外, 该镀膜电刀还能够保持温度均匀分 布, 减少组织过热损伤。

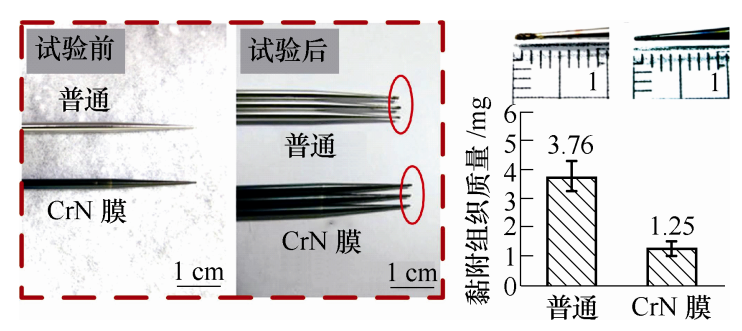

图 $6 \mathrm{CrN}$ 膜针与普通针组织粘附试验对比

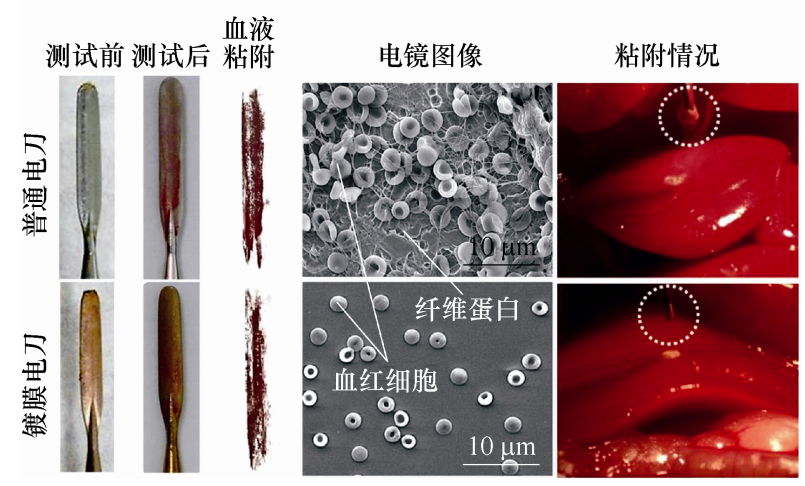

图 7 镀 DLC-Cu 膜电刀表面与普通电刀表面的 血液和组织粘附测试

1998 年, 土耳其加齐大学 CEVIKER 等 ${ }^{[18]}$ 发现 涂有薄层特氟龙(聚四氟乙烯, PTFE)的双极电凝可 降低组织粘附和炭化的程度。PTFE 因具有一定耐 热性、化学惰性、抗蛋白粘附性和低摩擦因数, 已 成为手术电极基材最常用的改性材料之一。此外, PTFE 还具有良好的介电稳定性, 但是经 PTFE 处理 的电极需要包含导电和非导电元件。如图 8 所示 ${ }^{[18]}$, CEVIKER 在双极电凝前端将PTFE 涂层设计成条纹 状, 同时包含涂层不导电表面和无涂层导电表面。 2017 年, 杨光等 ${ }^{[19]}$ 设计了一种表面涂有 PTFE 的高

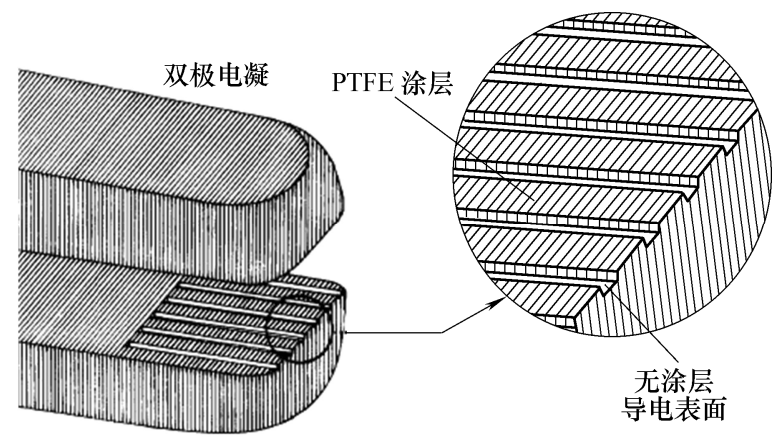

图 8 PTFE 涂层双极电凝
频电刀, 如图 9 所示。将聚四氟乙烯与电刀表面结 合, 并将薄膜制成篎眼状结构, 不仅保证了电刀的 导电性, 也可防止血液、软组织等在刀头表面形成 结痂。

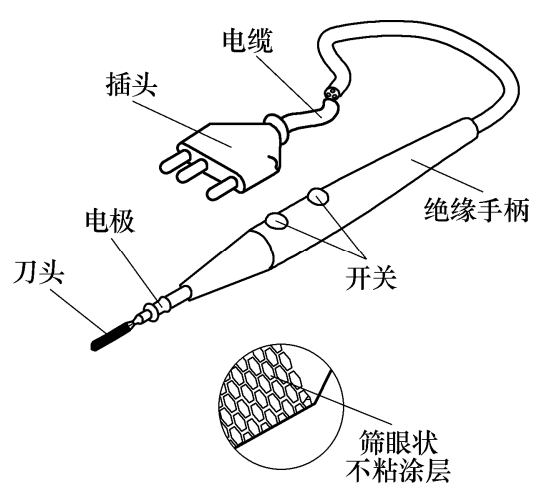

图 9 聚四氟乙烯涂层不粘电刀

\section{3 微结构型}

2013 年, CHENG 等 ${ }^{[20]}$ 设计了一种仿生高频电 刀, 通过在电刀表面加工类荷叶表面的超疏水结构, 使得电刀具有良好的疏血性能, 增强了刀头的不粘 性。试验测得该仿生刀头温度约为 $116{ }^{\circ} \mathrm{C}$, 与普通 电刀相比可减少温升超过 $17.3 \%$, 增加了表面散热, 对组织造成的热损伤更小。2014 年, 吉林大学韩志 武等 ${ }^{[21]}$ 以苏子叶、玉米叶等具有防粘脱附功能的植 物叶片为原型, 设计发明了一种仿生防粘高频电刀 刀头, 如图 10 所示 ${ }^{21}$ 。该发明将相同深度和宽度的 圆形、条形凹槽沿电刀长度方向相间排列, 纵向等 距排列, 使得手术时生物组织与刀片接触面积减少, 可降低组织炭化和粘附。且凹槽结构沿刀片长度方 向分布, 有利于组织顺向脱附, 同时凹槽增加了电 刀的表面积, 有助于散热。试验表明, 该电刀的最 小粘附质量较普通电刀的减少约 $39 \%$ 。

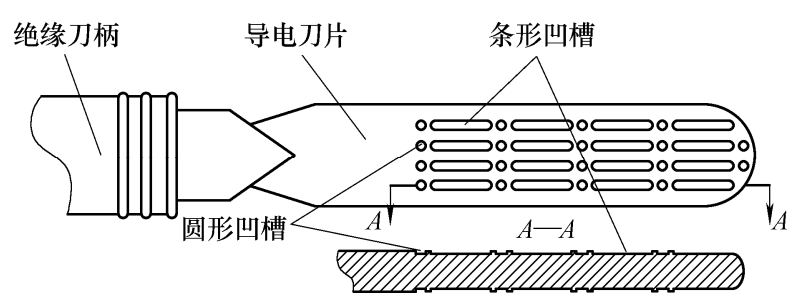

图 10 一种仿生防粘高频电刀示意图]

\section{4 复合型}

2017 年, 吉林大学韩志武等 ${ }^{[22]}$ 模仿玉米叶表皮 微观形貌在电刀表面构筑网状结构, 并覆盖了一层 $\mathrm{TiO}_{2}$ 涂层, 开发了一种仿生结构与 $\mathrm{TiO}_{2}$ 涂层耦合的 抗粘附电刀表面。在对新鲜分离的动物肝脏组织进 行的电切试验中, 相比未处理的和只有微结构或 $\mathrm{TiO}_{2}$ 涂层的电刀表面, 耦合仿生抗粘附电刀表面的 组织粘附最少, 表现出更优异的抗粘附性能, 如图 11 所示 ${ }^{[22]}$ 。网状结构使得生物组织与电刀表面之间 
存在更多空气隙, 二者无法充分接触, 增加了散热 面积, 有效减少了高温对邻近组织的热损伤。

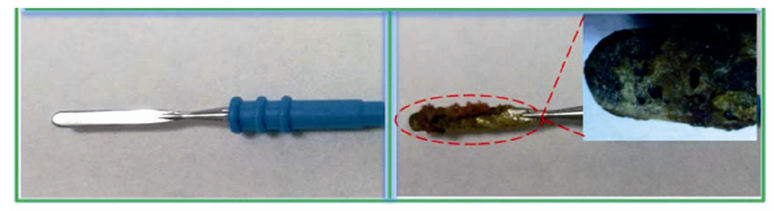

(a) 普通电刀及组织粘附情况

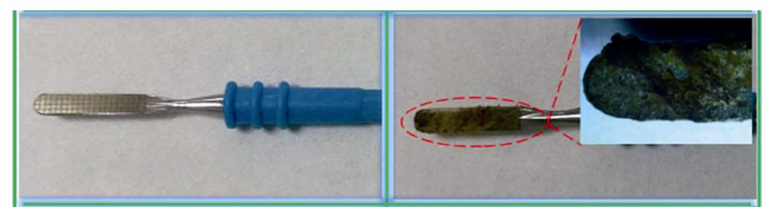

(b) 网状结构电刀及组织粘附情况

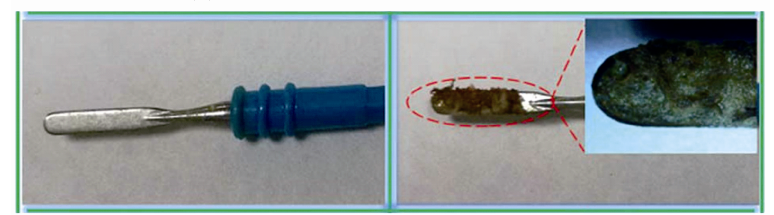

(b) $\mathrm{TiO}_{2}$ 涂层电刀及组织粘附情况

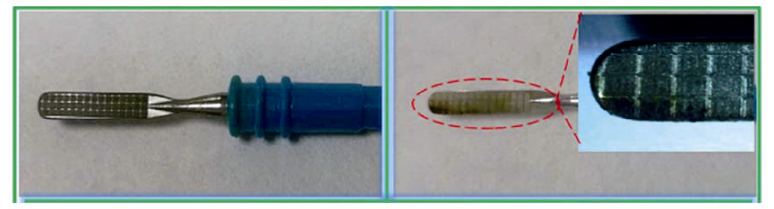

(d) 仿生耦合电刀及组织粘附情况

图 11 不同表面结构电刀切割组织粘附性对比

2018 年, 为减少手术中载能电刀表面的生物组 织粘附, 北京航空航天大学 ZHANG 等 ${ }^{[23-24]}$ 仿生猪 笼草唇缘区超润滑表面, 在电刀表面构筑微纹理结 构, 形成均匀排布的微坑, 经硅烷处理并填充硅油 形成微纹理液体注入表面(T-LIS)和制备了一种粗粘 毛化硅油注入表面(R-LIS)。这种液体注入表面引入 了润滑液膜层, 将电刀与生物组织的接触方式由固固接触转变为固-液-固接触, 避免了手术过程中生 物组织直接与电刀表面接触, 相比普通电刀表面和 硅烷处理粗糙电刀表面, 其不仅能显著降低组织的

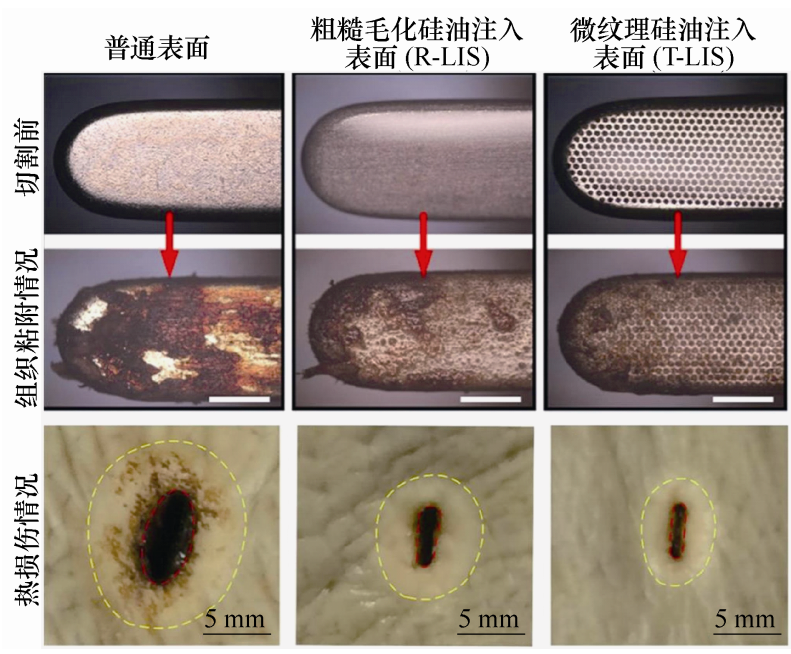

图 12 三种不同电刀切割猪肺组织试验对比
粘附力, 而且能减小热损伤创面。如图 12 所示 ${ }^{[23]}$, 通过对比三种载能电刀切割猪肺部组织的试验情 况, T-LIS 附着的生物组织较前两者明显减少,

R-LIS、T-LIS 相对于普通电刀表面残留组织质量分 别减少了约 $53 \%$ 和 $82 \%$, 最大粘附力可降低约 $42 \%$ 和 $66 \%$, 伤口面积仅为普通电刀的 $29 \%$ 和 $17 \%$ 。而 T-LIS 相对于 R-LIS 存储了更多的硅油, 其抗组织 粘附能力更为突出。

通过对比上述四种不同类型防粘脱附性高频电 刀, 可以发现, 辅助装置型电刀由于在电刀内部或 外部设置了专用防粘模块, 其不仅增加了电刀体积, 同时使用了过多外部设备, 进而增加了医生手术操 作难度。涂层型电刀广泛使用低表面能金属化合物、 有机物等作为刀具表面涂层材料, 涂层强度是否满 足要求、导电性是否良好等是选择的关键性因素。 此外, 有机物涂层在高温下容易被破坏且释放有毒 物质, 危害病人健康。西南交通大学万健飞等 ${ }^{[25]}$ 试 验发现 PTFE 涂层电刀仅在手术切割初期具有一定 的抗粘附性能, 但切割阻力大, 效率低下; 而随着 手术时间增加, 电刀与生物组织接触界面的电弧放 电会导致 PTFE 涂层烧蚀, 进而抗组织粘附性能被 削弱甚至丧失, 邻近组织受热创伤加剧。目前, 随 着人们对自然生物的认识逐步提高, 仿生微结构型 和仿生复合型(微结构/涂层耦合、微结构注入润滑 液等)等新型防粘脱附性高频电刀在减少组织粘附 质量、降低粘附力、减少热损伤面积等方面具有显 著成效, 逐渐成为该领域的研究重点与热点。

\section{2 脱附性高频电刀表面仿生模型}

目前, 仿生防粘脱附性医用高频电刀备受瞩目, 针对其表面脱附性能研究主要仿生模型有荷叶、玉 米苞叶、鲨鱼皮以及猪笼草等。

\section{1 荷叶表面模型}

荷叶表面因在自然界中具有超疏水、自清洁、 低粘附等效应, 自古以来便有 “出淤泥而不染” 的 美誉。随着现代科学逐渐向微纳米量级层面不断深 入, 荷叶疏水的谜底被揭开, 其主要原因是荷叶表 面由微米级凸细胞及附着在细胞上的纳米级蜡管层

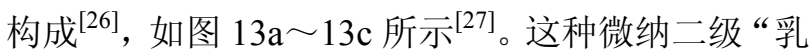
突状” 结构使得液滴与叶面之间存在空气隙, 减少 了表面与液滴的接触面积, 液滴便不能完全浸入结 构内部, 其属于 Cassie-Baxter 模型 ${ }^{[28]}$, 静态接触角 $\theta>150^{\circ}$ ，达到超疏水状态，如图 13d 所示。2009 年, 德国波恩大学的研究人员通过复制荷叶表面微 纳结构, 测得水滴在其表面粘附力约为光滑平面的 
$1 / 4^{[27]}$ 。将电刀表面刻蚀形成类荷叶 “乳突状” 结构, 可使血滴在电刀表面的静态接触角大于 $150^{\circ}$, 降 低组织粘附力并增加散热和减少温升 ${ }^{[20]}$ 。

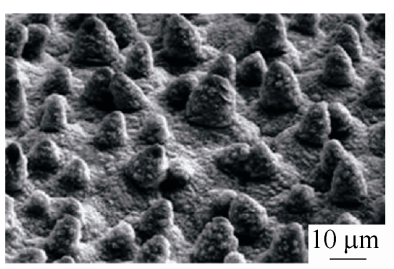

(a) 荷叶表面微观结构

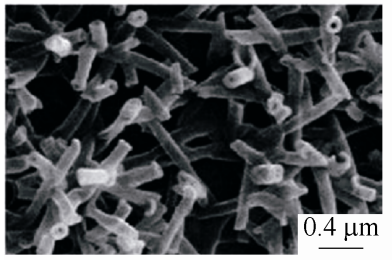

(c) 纳米级疏水蜡管

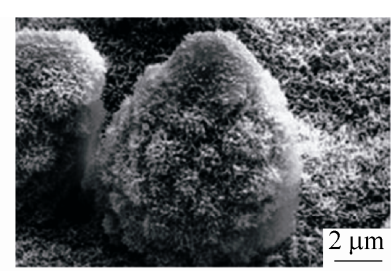

(b) 微米级凸细胞

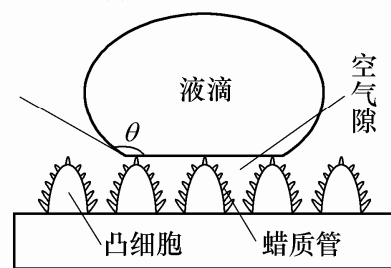

(d) 荷叶疏水模型
图 13 荷叶表面微观结构电镜图像及疏水模型

\section{2 玉米苍叶表面模型}

在我国北方，人们日常蒸制面食的时候为防止 面食出蒸笼时底部被粘掉皮, 常选用新鲜玉米苞叶 垫底。可见, 新鲜玉米苍叶在高温、湿润的蒸制环 境下具有良好的防粘效果。而在外科手术过程中, 医用高频电刀也是处于一个高温、湿润的环境下, 因此二者所处环境具有一定共通性。

2017 年, 吉林大学韩志武等 ${ }^{[29]}$ 对高温和高湿 条件下新鲜玉米苍叶的抗粘附性能进行研究, 研究 人员设定试验温度范围 $23 \sim 100{ }^{\circ} \mathrm{C}$, 湿度范围 $18 \% \sim 100 \%$, 发现在湿度 $60 \% \sim 100 \%$, 温度 $80 \sim$ $90{ }^{\circ} \mathrm{C}$ 范围内, 玉米苞叶的粘附力急剧减少至 $2 \mathrm{nN}$ 左右。通过扫描电镜发现, 玉米苞叶表皮主要由网 格区域、随机分布的小气孔等结构组成。网格区域 由横向脊和纵向脊构成, 其横向脊宽度为 $5 \sim 8$ $\mu \mathrm{m}$, 间距为 $20 \sim 40 \mu \mathrm{m}$, 呈波浪状; 纵向脊宽度为 $2 \sim 5 \mu \mathrm{m}$, 间距随机无规律。图 $14 \mathrm{a}$ 所示 ${ }^{[29]}$ 为玉米 苞叶及表皮微观结构。为解释玉米苞叶的抗粘附机 理, 建立了如图 $14 \mathrm{~b}$ 所示玉米苍叶表面三维模型, 其表面横向和纵向脊相互交错, 形成小气穴, 可减 少物体与叶面之间的实际接触面积。在试验过程 中, 叶面与物体的粘附力主要由毛细力和范德华力 组成, 在第一阶段 $\left(23 \sim 80{ }^{\circ} \mathrm{C}\right.$ 、相对湿度 $\left.18 \% \sim 60 \%\right)$ 范德华力占主导地位, 粘附力主要与材料和微观结 构有关, 此时叶面的粘附力较大; 进入第二阶段 (80 $90{ }^{\circ} \mathrm{C}$, 相对湿度 $60 \% \sim 90 \%$ ), 湿度较小时, 毛细力与范德华力相互抵抗, 叶面粘附力减小, 而 随着湿度增加, 蒸汽冷凝形成水膜, 引起粘附力增 加, 但随着温度升高, 气流在横向波状脊顶部流动 加快, 使得叶面粘附力降低; 在第三阶段( 90
$100{ }^{\circ} \mathrm{C}$, 相对湿度 $\left.90 \% \sim 100 \%\right)$, 蒸汽冷凝急剧增 加, 气穴中形成多层水膜, 叶片与物体的接触转换 为水膜与物体的接触。通过对玉米苞叶抗粘附的深 入研究, 吉林大学研究人员将玉米苞叶表面微观结 构引入高频电刀, 构建了一种微网格结构 $/ \mathrm{TiO}_{2}$ 涂 层耦合表面, 有效地减少了高频电刀表面的生物组 织粘附质量 ${ }^{[22]}$ 。

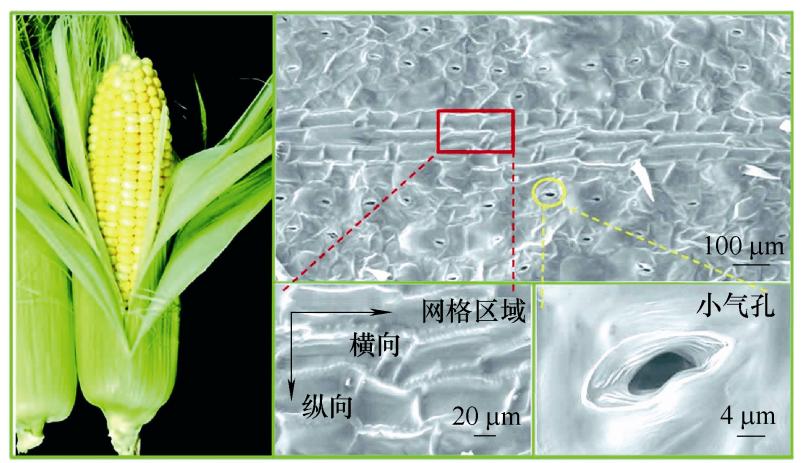

(a) 玉米苍叶及表皮微观结构

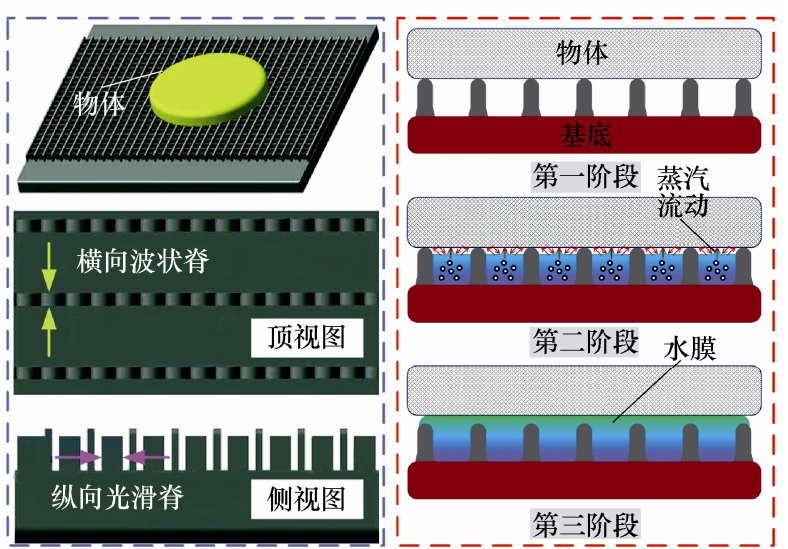

(b) 玉米苍叶表面三维模型

图 14 玉米苍叶表皮微观结构及抗粘附模型

\section{3 鲨鱼皮表面模型}

鲨鱼等大型海洋动物终年生活在海水中, 其表 皮却始终不会附着任何海洋生物, 经科学家发现, 鲨鱼皮表面存在特殊的生理结构。图 15 所示为鲨鱼 皮表面微观结构 ${ }^{[30]}$, 由许多肋状盾鳞组成, 其朝向 一致, 尾部交替重叠, 每片盾鳞肋突处光滑而沟槽 处相对粗粘; 同时鲨鱼通过分泌黏液附着表皮，降 低皮肤表面能, 从而使得海洋众多生物难以附着 ${ }^{[31]}$ 。 鉴于鲨鱼表皮这种独特结构，其仿生模型大量应用 于轮船防污 ${ }^{[32]}$ 、医学防粘抑菌 ${ }^{[33]}$ 等重要领域。2018 年，陕西科技大学杨立军等 ${ }^{[34-35]}$ 在高频电刀表面构 建仿生鲨鱼皮肋状盾鳞结构, 增加了电刀表面的疏 水性, 其接触角最大可提升 $21 \%$; 该结构经仿真试 验可减少 $2.16 \%$ 的切割阻力, 并提出猪血环境下仿 生鲨鱼皮表面的最优减阻参数为鳞片尺寸为 600 $\mu \mathrm{m}$, 间距为 $150 \mu \mathrm{m}$; 且相较于普通电刀, 该仿生 电刀的组织粘附量最大可减少 $16.91 \%$ 。 


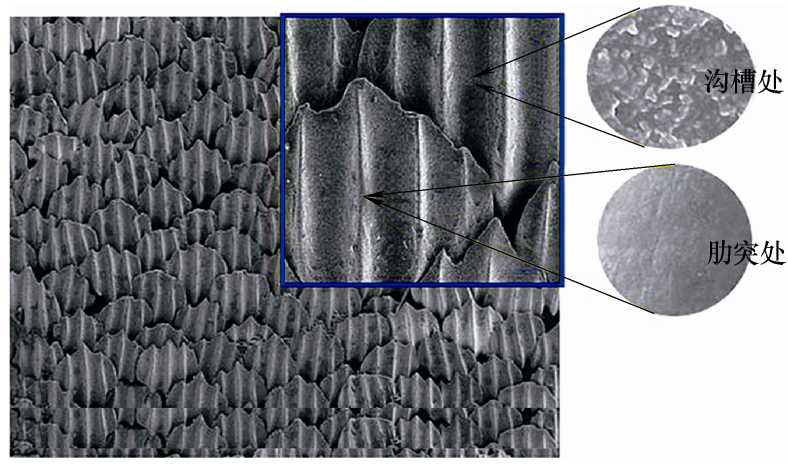

图 15 鲨鱼皮表面肋状盾鳞结构

\section{4 猪笼草唇缘区超润滑表面模型}

一般的脱附微结构中由于存在空气隙, 其表面 的液滴在重力条件下无法浸入, 但液滴无法承受外 在压力, 一旦存在压力便迫使外来液体渗透浸入微 结构中, 便很难实现液体的完全清除。2011 年, 哈 佛大学 WONG 等 ${ }^{[36]}$ 发现猪笼草唇缘区排斥异物的 机制与荷叶表面存在不同, 荷叶通过表面的微纳尺 度结构直接排斥液体, 而猪笼草唇缘区则是利用微 结构 “锁住” 自身的液体去排斥其他外来物。受此 启发, 该团队提出了一种新颖的仿生模型, 称之为 “光滑液体注入多孔表面(SLIPS)”, 如图 16a 所 示 ${ }^{[36]}$ 。

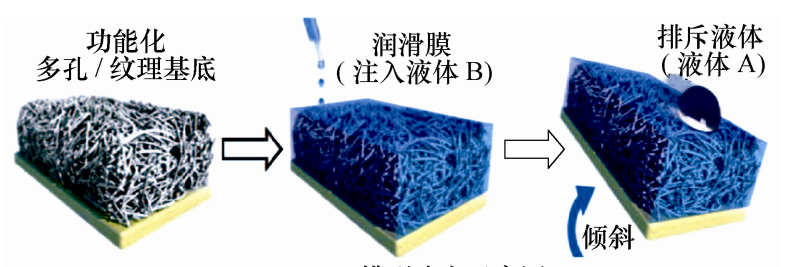

(a) SLIPS 模型建立示意图

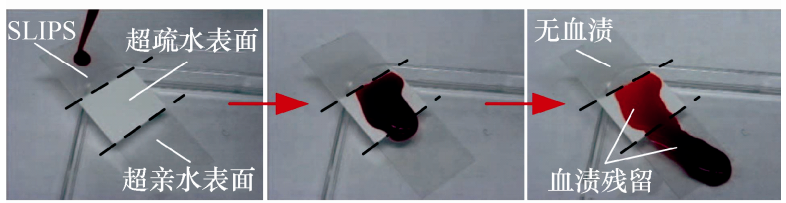

(b) SLIPS 血液防粘附性能测试

图 16 SLIPS 表面模型及血液粘附测试

通过在多孔或纹理基材内注入润滑液以排斥其 他液体, 并提出该模型建立的三个标准: (1) 润滑液 被基材吸入后, 能润湿并稳定的粘附在基材内; (2) 固体基材必须优先被润滑液体润湿而不是想要排斥 的液体润湿; (3) 注入液体与被排斥液体不能混溶。 如图 16b 所示, 研究者将 SLIPS、超疏水特氟龙多 孔膜和亲水玻璃表面进行血液排斥能力测验, 可以 发现, 血液在 SLIPS 表面并无残留, 其抗血液粘附 性能明显优于后两者。2015 年, 哈佛大学 TESLER 等 ${ }^{[37]}$ 报道了将 SLIPS 引入普通手术刀表面后, 其表 面能近乎完全地防止血液粘附, 且极大地增强了手 术刀的抑菌效果。

2016 年, 北京航空航天大学陈华伟、张德远课
题组发现猪笼草口缘区表面具有液体单方向连续搬 运能力 ${ }^{[38-39]}$ 。如图 17a 所示, 猪笼草唇缘区表面由近 乎平行排列的沟槽和 “鸭嘴状” 楔形盲孔阵列结构 组成, 楔形盲孔顶端封闭; 具有拱形外轮廓及尖锐 边缘，并呈梯度分布。这种结构特征可形成 “闭口 梯度泰勒毛细升”, 可使毛细升液体体积提高约 $40 \%$, 液体保存时间延长约 2 倍。该课题组将猪笼草液体 单方向连续搬运机制复制于高频电刀表面，其具体 过程如图 $17 \mathrm{~b}$ 所示 ${ }^{[40]}$ 。高频电刀表面高密度与低密 度柱状阵列对称分布在微沟槽两边, 润滑液受毛细 力作用沿中心微沟槽连续输送, 并自发地向两边阵 列微通道上扩散, 最终形成自润滑抗粘附表面。

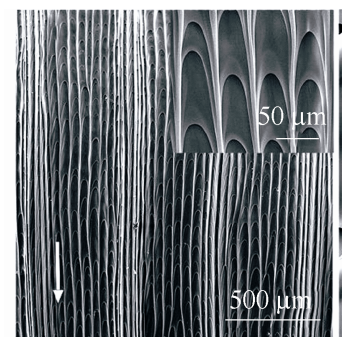

猪笼草口缘区表面平行 分布的沟槽和楔形盲孔结构

(a) 猪笼草口缘区表面微观结构的扫描电镜图像

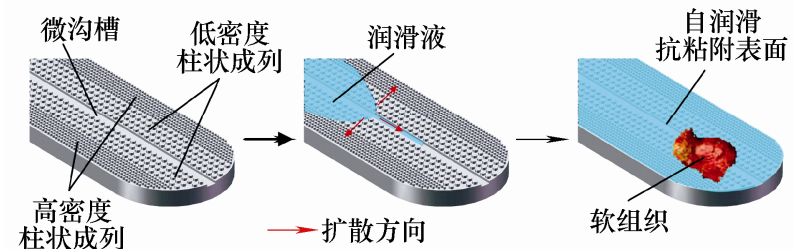

(b) 防生猪笼草梯度润湿性自润滑抗粘附表面
可见，将猪笼草唇缘区模型应用于高频电刀表 面, 不仅可以改变以往手术过程中普通高频电刀与 血液、软组织的接触方式(即固-固接触形式向固-液固接触形式转变), 而且可以连续向高频电刀表面输 送润滑液，保证血液、软组织等难以附着在电刀表 面，从而实现医用高频电刀的脱附效果。

上述对自然界具有优异脱附性能动植物的相关 研究成果, 不仅为构造医用高频电刀表面脱附结构 或涂层提供了理论指导，而且引领脱附性医用高频 电刀的相关研究步入了新的发展方向。可以预见, 今后的脱附性高频电刀研究仍会以自然界的仿生脱 附模型为重点, 推动相关理论和技术进行创新。

\section{3 高频电刀脱附表面制造方法}

相对于传统机械加工技术, 各种精密型微加工 技术更利于构建医用高频电刀脱附表面，可制造出 
多种具有不同形貌、不同维度、更小尺度的结构或 涂层。而随着工业领域中对表面脱附功能结构、表 面热功能结构、表面光功能结构等 ${ }^{[41]}$ 大量应用, 相 关制造方法及技术成为了影响产品性能的关键性 因素。

1959 年, 美国物理学家费曼针对超密集型集成 电路元件难以小型化至纳米级的技术壁垒, 提出了 “自底向上” 的制造策略(Bottom-Up Strategy), 使 之可从原子或分子量级构建纳米器件 ${ }^{[42]}$ 。现如今, 该策略也同样适用于脱附性医用高频电刀制造领 域, 并与之对立的称为 “自顶向下” 策略(Top-Down

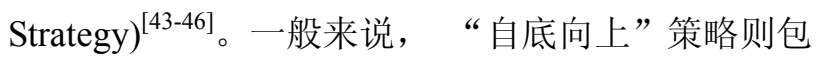
含电化学沉积法、表面喷丸法、溶胶凝胶法等; “自 顶向下” 策略包括光学曝光(光刻)、激光刻蚀、化 学刻蚀、阳极氧化等加工方法。前者制造出的表面 微结构是随机的, 且形貌不可控制, 在大规模生产 中具有一定局限性, 而后者可以对表面形貌进行高 度控制, 是最常用的脱附性结构制造策略 ${ }^{[44,46-47]}$ 。 研究者一直试图寻找适合不同脱附结构的加工方法 并将其运用到医用高频电刀表面, 从综合加工复杂 程度来看, 一般可分为单步法与多步法。

\section{1 单步法}

在探索脱附性医用高频电刀表面的过程中, 许 多研究者采用诸如激光刻蚀、物理沉积、喷涂等方 法一步完成脱附表面结构或涂层的构建。激光刻蚀 法是最常用的微结构制造方法之一, 其通过聚焦产 生瞬时高温使电刀的加工部位气化而清除废料, 对 周围区域的材料影响较小, 且能够精确控制微结构 生成。此外, 气化的金属极易在加工部位周围快速 凝结, 形成纳米颗粒并附着在加工形成的微米级结 构上, 进而形成微纳米双尺度结构。

2013 年, CHENG 等 ${ }^{[20]}$ 利用不同脉冲激光在电 刀表面刻蚀形成尺寸小于 $5 \mu \mathrm{m}$, 间距小于 $9 \mu \mathrm{m}$, 呈周期性分布的微纳米颗粒, 使电刀具有良好的疏 血防粘性和散热性。2017 年, LIN 等 ${ }^{[48]}$ 使用飞秒激 光脉冲直接对高频电刀进行表面改性, 在其表面形 成的直径 $20 \sim 50 \mathrm{~nm}$ 的微坑和直径 $100 \sim 200 \mathrm{~nm}$ 球 形颗粒构成纳米多晶 $\mathrm{FeO}_{x}$ 膜, 增强了电刀的导热性 并有效减少组织粘连问题。

物理沉积法和喷涂法最适用于不粘涂层与医用 高频电刀表面结合。2015 年, 台北医学大学 HSIAO 等 ${ }^{[49]}$ 利用射频磁控溅射方法在高频电刀表面沉积 一层厚度约 $300 \mathrm{~nm}$ 的 DLC-Cu(含铜类金刚石膜)薄 膜, 用于减少电刀的组织粘附量和热损伤情况。2018 年, 日本庆应义塾大学 PARK 等 ${ }^{[50]}$ 将疏水 $\mathrm{SiO}_{2}$ 气溶 胶直接喷涂在电外科手术双极钳表面, 其水接触角
可达到 $153.4^{\circ}, \mathrm{SiO}_{2}$ 薄膜可延缓温度升高并阻碍组 织粘附, 因而在高温下比无涂层的普通双极钳具有 更低组织粘附力和更好抗组织粘附特性。

\section{2 多步法}

单步法制造的脱附结构往往单一, 不具多样性, 且高频电刀在手术过程中由于切割摩擦、电弧放电 等作用, 微结构(或涂层)容易磨损(或剥落), 其脱附 能力与寿命亦相当有限。针对这一现象, 脱附性医 疗刀具表面在研究过程中往往使用多种方法相结 合、多学科交叉的方式加工制造。

2015 年, 哈佛大学 TESLER 等 ${ }^{[37]}$ 在室温下利用 电化学沉积法在不锈钢手术刀表面直接形成一层极 其坚固的厚度为 $10 \sim 20 \mathrm{~nm}$ 的多孔氧化铇薄膜, 随 即通过化学氟化处理并注入医用级全氟化碳润滑 剂, 获得具有完全疏血能力和高抑菌效果的手术刀 表面。2017 年, 吉林大学韩志武等 ${ }^{[22]}$ 通过激光打标 技术在高频电刀表面刻蚀形成网格状结构, 随后利 用化学溶胶凝胶法制备二氧化钛凝胶, 并旋涂于电 刀表面形成厚度为 $10 \sim 15 \mu \mathrm{m}$ 二氧化钛涂层, 最终 在高频电刀上构成网格结构/二氧化钛涂层耦合脱 附表面。

2016 年, 北京航空航天大学 ZHANG 等 ${ }^{[51]}$ 首次 提出以光刻胶为媒介, 利用光刻辅助化学刻蚀方法, 并控制刻蚀时间为 $10 \mathrm{~min}$, 刻蚀深度约 $5.08 \mu \mathrm{m}$, 在不锈钢表面形成均匀分布的微柱结构, 即不锈钢 纹理表面。将该表面经硅烷偶联剂(OTS)功能化处理 后浸入硅油, 形成类似猪笼草唇缘区的光滑液体注 入表面(LIS)。试验测得 LIS 的水滚动角约为 $2^{\circ}$; 在 $250^{\circ} \mathrm{C}$ 高温下, 通过与猪肉组织接触 4 次, LIS 不锈 钢表面相对于光滑不锈钢表面粘附质量减少了约 $89 \%$, 表明了 LIS 具有优异的抗粘附能力。 2018 年, ZHANG 等 ${ }^{[23]}$ 以类似的方法将 PDMS(聚二甲基硅氧 烷)模板上的微纹理结构转印至高频电刀表面, 电刀 表面经电化学腐蚀形成深约 $4 \mu \mathrm{m}$ 微坑阵列; 为增加 表面的硅油亲和性, 表面先经硅烷偶联剂(OTS)处理 再注入硅油, 获得 LIS 抗粘附表面, 防止手术过程 中血液、软组织等在高频电刀表面粘连, 该电刀的 制造过程如图 18 所示 ${ }^{[22]}$ 。

以上研究可以发现, 在脱附性高频电刀的制 造过程中, 制造工艺与工艺路线等方面尚未形成 统一的标准, 仍处于基础研究阶段, 未能实现脱 附性医用高频电刀制造产业化。因而, 针对新型 脱附高频电刀, 在建立和完善具体的理论分析模 型, 改进现有的制造工艺, 寻求合理的、绿色的 制造方法，探索高效的工艺路线等方面具有非常 重要的现实意义。 


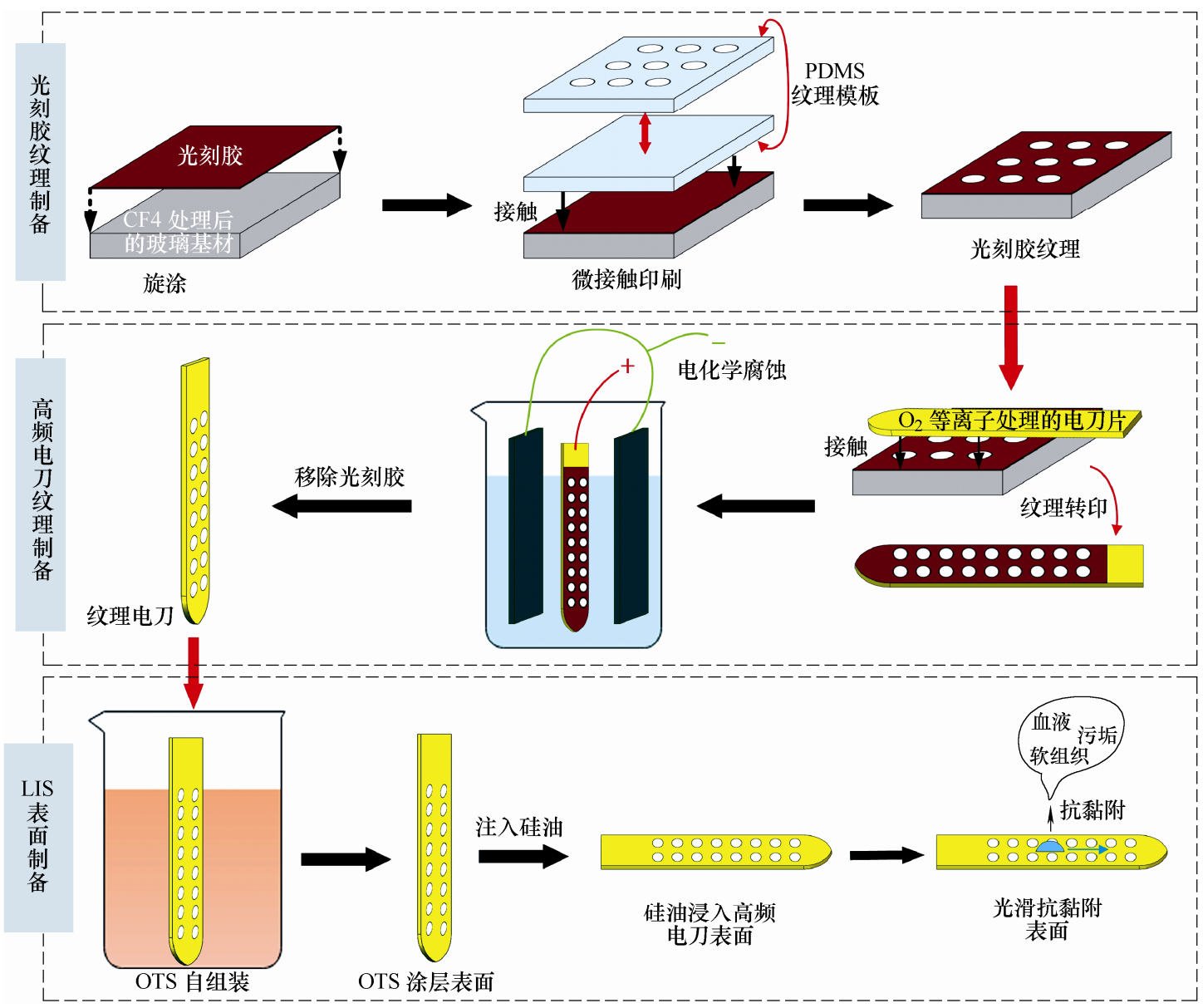

图 18 多步法制造医用高频电刀 LIS 脱附表面

\section{4 结论}

脱附性医用高频电刀由于其特殊的疏血、抗组 织粘附和抑菌等功能, 在外科、微创手术等医疗领 域具有非常重要的研究与应用价值。目前, 脱附性 医用高频电刀的研究重心逐渐向仿生学过渡, 相关 研究处于初步探索阶段, 其相关理论未成体系, 制 造技术尚未成熟，同时制得的脱附性高频电刀缺乏 临床试验, 缺少临床试验数据指导。国内北京航空 航天大学张德远、陈华伟教授课题组和吉林大学韩 志武教授课题组在高频电刀表面生物组织脱附功能 的相关研究已取得了阶段性进展, 而国外相关研究 报道较少。结合当前脱附性高频电刀的研究现状和 应用需求, 今后可从以下几个方面进行研究。

(1) 加强对多场协同作用下普通高频电刀手术 中生物组织的粘附行为分析, 为构建脱附性医用高 频电刀提供理论支持。高频电刀在手术过程中表面 同时发生着液体(血液、组织液等流场)和固体(软组 织、脂肪等)的粘附行为(粘附力场), 两者在电刀表 面的粘附机制存在着一定差异, 同时所以需要分别 对表面存在的液体和固体粘附机制进行探索; 基于
电刀高频放电(电场)加热软组织进行切割和凝血的 原理, 分析在工作温度下(温度场)电刀表面血液和 软组织发生的形态和性质变化, 产生结痂和粘附现 象的成因; 综合分析温度场、电场、流场和力场等 变化所引起的血液、软组织在高频电刀表面接触粘 附行为的变化, 确定温度场、电场、流场及力场等 与粘附力、粘附质量等参数的关系。

(2) 加强对猪笼草唇缘区超润湿表面模型的系 统性研究。目前该模型是学者们采用到电刀表面最 为普遍的, 通过在多孔微结构中填入润滑油, 隔离 电刀与生物组织, 达到减少血液、软组织粘附的目 的。因此, 润滑液在微结构中的保留程度对刀具的 脱附性能具有很大影响, 通过分析、建立合理的微 结构模型可以最大程度保留或输送润滑液, 增强电 刀的耐用性。此外, 还须考虑手术时切割组织时的 压力问题，压力过大会将生物组织挤入微结构中, 影响电刀防粘脱附性能。

（3）针对高频电刀的脱附性研究, 可加强对仿 生微结构模型的电、热力学性能研究。高频电刀主 要通过刀尖放电并形成高温, 用于组织切割及止血。 不合理微结构的引入, 会造成电刀温度分布不均, 易造成组织高温灼烧、创面畸形、表面切割阻力增 
大等问题。因而, 研究高频电刀表面微结构的电、 热力学性能具有重要的指导意义。

(4) 寻求合理的脱附微结构或涂层的制造方 法, 发展新的、绿色的制造工艺。当前各类仿生结 构的制造方法以工业应用居多，而仿生脱附性医用 高频电刀应以人为本, 寻求和发展绿色环保、无毒 无菌无害的原材料、制造方法和工艺条件等是保证 脱附性高频电刀品质的重要因素。

(5) 探索新的仿生脱附理论模型。大自然是神 秘的, 为我们生活、生产中的问题提供了许多行之 有效的解决方案。师法自然, 探索新的仿生脱附模 型, 可为仿生脱附性高频电刀的相关研究及应用开 辟新的路径。

\section{参 考 文 献}

[1] OCHSNER J. Surgical knife[J]. Texas Heart Institute Journal, 2009, 36(5): 441-443.

[2] 杨勇, 田志杰. 现代外科手术刀[J]. 临床外科杂志, 2008, 16(7): 437-438.

YANG Yong, TIAN Zhijie. Modern surgical scalpel[J]. Journal of Clinical Surgery, 2008, 16(7): 437-438.

[3] 王锦航, 董福生, 董玉英. 现代手术刀的研究进展 [J]. 医学理论与实践, 2015, 28(4): 447-449.

WANG Jinhang, DONG Fusheng, DONG Yuying. Research progress of modern scalpel[J]. The Journal of Medical Theory and Practice, 2015, 28(4): 447-449.

[4] 周伟伟, 穆燕. 高频电刀的常见意外伤害原因分析及预 防进展[J]. 护理学报, 2012, 19(12): 14-16.

ZHOU Weiwei, MU Yan. Cause Analysis and Prevention Progress of Common Accidental Injuries of High Frequency Electrotome[J]. Journal of Nursing(China), 2012, 19(12): 14-16.

[5] JI G W, WU Y Z, WANG X, et al. Experimental and clinical study of influence of high-frequency electric surgical knives on healing of abdominal incision[J]. World Journal of Gastroenterology: WJG, 2006, 12(25): 4082.

[6] DODDE R E, GEE J S, GEIGER J D, et al. Monopolar electrosurgical thermal management for minimizing tissue damage[J]. IEEE Transactions on Bio-Medical Engineering, 2012, 59(1): 167-173.

[7] LOFFER F D, BRADLEY L D, BRILL A I, et al. Hysteroscopic fluid monitoring guidelines: From the ad hoc committee on hysteroscopic fluid guidelines of the American Association of Gynecologic Laparoscopists[J]. The Journal of the American Association of Gynecologic Laparoscopists, 2000, 7(1): 167-168.

[8] 张同喜. 附着力、内聚力与润湿性的简明判据 [J]. 青海 大学学报, 2008, 26(1): 77-79.
ZHANG Tongxi. Concise criteria for adhesion, cohesion and wettability[J]. Journal of Qinghai University, 2008, 26(1): 77-79.

[9] ZHENG L, WAN J, LONG Y, et al. Effect of high-frequency electric field on the tissue sticking of minimally invasive electrosurgical devices[J]. Royal Society Open Science, 2018， 5(7): 180125.

[10] 郑建都.一种不粘电刀及电刀头的冷却方法: 中国, 201410460681.X[P]. 2014-11-26.

ZHENG Jiandu. A non-sticking electrome amd cooling method for its head: China, 201410460681.X[P]. 2014-11-26.

[11] YAO G, ZHANG D, GENG D, et al. Improving anti-adhesion performance of electrosurgical electrode assisted with ultrasonic vibration[J]. Ultrasonics, 2018, 84: 126-133.

[12] 李明守, 吴长兰.一种内置加热单元的手术刀: 中国, 201710759377.9[P]. 2018-01-19.

LI Mingshou, WU Changlan. A surgical scapel with built-in heating unit : China, 201710759377.9[P]. 2018-01-19.

[13] HSU Y L, LEE C H, CHIU S M, et al. Anti-Sticking Properties of PVD $\mathrm{CrWN}_{x}, \mathrm{CrO}_{x}$ and $\mathrm{ZrO}_{x}$ Coatings on Medical Electrode Application[J]. Defect \& Diffusion Forum, 2010, 297-301: 656-663.

[14] OU K L, CHU J S, HOSSEINKHANI H, et al. Biomedical nanostructured coating for minimally invasive surgery devices applications : Characterization, cell cytotoxicity evaluation and an animal study in rat[J]. Surgical Endoscopy, 2014, 28(7): 2174-2188.

[15] CHENG H Y, OU K L. The application of advanced nanostructured film in electrosurgical device: Anti-sticking behavior and thermal injury[J]. Journal of Nanomedicine \& Nanotechnology, 2015, 06(3): 1-8.

[16] OU K L, WENG C C, SUGIATNO E, et al. Effect of nanostructured thin film on minimally invasive surgery devices applications: Characterization, cell cytotoxicity evaluation and an animal study in $\operatorname{rat}[\mathrm{J}]$. Surgical Endoscopy, 2016, 30(7): 3035-3049.

[17] SHEN Y D, LIN L H, CHIANG H J, et al. Research of electrosurgical unit with novel antiadhesion composite thin film for tumor ablation: Microstructural characteristics, thermal conduction properties, and biological behaviors[J]. Journal of Biomedical Materials Research Part B: Applied Biomaterials, 2016, 104(1): 96-105.

[18] ÇEVIKER N, KESKIL S, BAYKANER K. A new coated bipolar coagulator: Technical note[J]. Acta Neurochirurgica, 1998, 140(6): 619-620.

[19] 杨光, 段海真, 邓崇第, 等. 一种不粘高频电手术刀: 
中国, 201720045622.5[P]. 2018-04-17.

YANG Guang, DUAN Haizhen, DENG Chongdi, et al. A non-sticky high frequency electrome : China , 201720045622.5[P]. 2018-04-17.

[20] CHENG C W, LIN C Y, TSENG W P, et al. Electrosurgical unit with micro/nano structure and the manufacturing method thereof: U.S., 13/337, 540[P]. 2013-05-30.

[21] 韩志武, 曹会娜, 关会英, 等. 一种仿生防粘高频电刀 刀头：中国，201410153396.3[P]. 2014-07-02.

HAN Zhiwu, CAO Huina, GUAN Huiying, et al. A bionic anti-sticking high frequency electrome' head: China, 201410153396.3[P]. 2014-07-02.

[22] HAN Z, FU J, FENG X, et al. Bionic anti-adhesive electrode coupled with maize leaf microstructures and TiO2 coating[J]. RSC Advances, 2017, 7(72) : 45287-45293.

[23] ZHANG P, LIU G, ZHANG D, et al. Liquid-Infused surfaces on electrosurgical instruments with exceptional antiadhesion and low-damage performances[J]. ACS Applied Materials \& Interfaces, 2018, 10(39) : 33713-33720.

[24] 刘光, 张鹏飞, 陈华伟, 等. 载能电刀仿生防粘表面技 术[J]. 机械工程学报, 2018, 54(17): 21-27.

LIU Guang, ZHANG Pengfei, CHEN Huawei, et al. Bio-inspired anti-adhesion surfaces of electrosurgical scalpel[J]. Journal of Mechanical Engineering, 2018, 54(17): 21-27.

[25] 万健飞, 郝汝飞, 龙运江, 等. PTFE 涂层抗粘附电极 切割效率和抗粘附性能的时变性研究 [J]. 机械工程学 报，2018，54(17): 2-7.

WAN Jianfei, HAO Rufei, LONG Yunjiang, et al. Research on the variations of the incision efficiency and anti-stickong performance of PTFE-coated electrode with operation time[J]. Journal of Mechanical Engineering, 2018, 54(17): 2-7.

[26] BARTHLOTT W, NEINHUIS C. Purity of the sacred lotus, or escape from contamination in biological surfaces[J]. Planta, 1997, 202(1): 1-8.

[27] KOCH K , BHUSHAN B , BARTHLOTT W. Multifunctional surface structures of plants: An inspiration for biomimetics[J]. Progress in Materials Science, 2009, 54(2): 137-178.

[28] CASSIE A, BAXTER S. Wettability of porous surfaces[J]. Transactions of the Faraday society, 1944, 40: 546-551.

[29] HAN Z, FU J, FANG Y, et al. Anti-adhesive property of maize leaf surface related with temperature and humidity[J]. Journal of Bionic Engineering, 2017, 14(3): 540-548.
[30] PU X, LI G, HUANG H. Preparation, anti-biofouling and drag-reduction properties of a biomimetic shark skin surface[J]. Biology Open, 2016， 5(4): 389-396.

[31] 邵静静, 萄存国, 张金伟, 等. 鲨鱼皮仿生防污研究 [J]. 涂料工业，2008，38(10): 39-41.

SHAO Jingjing, LIN Cunguo, ZHANG Jinwei, et al. Study on shark skin's bionical and antifouling properties[J]. Paint \& Coatings Industry，2008，38(10): $39-41$.

[32] CHEN H, XIN Z, MA L, et al. Investigation on large-area fabrication of vivid shark skin with superior surface functions[J]. Applied Surface Science, 2014, 316(1): 124-131.

[33] MAY R M, MAGIN C M, MANN E E, et al. An engineered micropattern to reduce bacterial colonization, platelet adhesion and fibrin sheath formation for improved biocompatibility of central venous catheters $[\mathrm{J}]$. Clinical and Translational Medicine, 2015，4(1): 9.

[34] LI C, YANG L J, YAN C C, et al. Biomimetic anti-adhesive surface micro-structures of electrosurgical knife fabricated by fibre laser[J]. Journal of Laser Micro Nanoengineering, 2018, 13(3): 309-313.

[35] 杨立军, 刘楠, 闻程程, 等. 高频电手术刀表面激光制 备仿生鲨鱼皮微结构的研究 [J]. 陕西科技大学学报, 2018, 36(5): 141-145, 158.

YANG Lijun, LIU Nan, YAN Chengcheng, et al. Study on biomimetic sharkskin microstructure prepared by laser on the surface of high-frequency electrome[J]. Journal of Shaanxi University of Science \& Technology, 2018, 36(5): 141-145, 158.

[36] WONG T S, KANG S H, TANG S K, et al. Bioinspired self-repairing slippery surfaces with pressure-stable omniphobicity[J]. Nature, 2011, 477(7365): 443.

[37] TESLER A B, KIM P, KOLLE S, et al. Extremely durable biofouling-resistant metallic surfaces based on electrodeposited nanoporous tungstite films on steel[J]. Nature Communications, 2015，6: 8649.

[38] CHEN H, ZHANG P, ZHANG L, et al. Continuous directional water transport on the peristome surface of Nepenthes alata[J]. Nature，2016，532(7597): 85.

[39] 陈华伟, 张鹏飞, 张力文, 等. 猪笼草口缘区表面液体 单方向连续搬运机制 $[\mathrm{J}]$. 中国科学基金, 2016 (3): 217-219.

CHEN Huawei, ZHANG Pengfei, ZHANG Liwen, et al. Continuous directional water transport on the peristome surface of Nepenthes alata[J]. Bulletin of National Natural Science Foundation of China, 2016 (3): 217-219.

[40] LIU G, ZHANG P, LIU Y, et al. Self-lubricanting slippery surface with wettability gradients for 
anti-sticking of electrosurgical scalpel[J]. Micromachines (Basel), 2018, 9(11): 591.

[41] 汤勇, 周明, 韩志武, 等. 表面功能结构制造研究进展 [J]. 机械工程学报, 2010, 46(23): 93-105.

TANG Yong, ZHOU Ming, HAN Zhiwu, et al. Recent research on manufacturing technologies of founctional surface structure[J]. Journal of Mechanical Engineering, 2010, 46(23): 93-105.

[42] SABLON K. Nanoelectrodes for molecular devices: A controllable fabrication[J]. Nanoscale Research Letters, 2008, 3(7): 268.

[43] CELIA E, DARMANIN T, DE GIVENCHY E T, et al. Recent advances in designing superhydrophobic surfaces[J]. Journal of Colloid and Interface Science, 2013, 402: 1-18.

[44] BELLANGER H, DARMANIN T, TAFFIN de GIVENCHY E, et al. Chemical and physical pathways for the preparation of superoleophobic surfaces and related wetting theories[J]. Chemical Reviews, 2014, 114(5): 2694-2716.

[45] JIANG T, GUO Z, LIU W. Biomimetic superoleophobic surfaces: focusing on their fabrication and applications[J]. Journal of Materials Chemistry A, 2015, 3(5): 1811-1827.

[46] OH J K, LU X, MIN Y, et al. Bacterially antiadhesive, optically transparent surfaces inspired from rice leaves[J]. ACS Applied Materials \& Interfaces, 2015, 7(34): 19274-19281.

[47] JUNG M, KIM T, KIM H, et al. Design and fabrication of a large-area superhydrophobic metal surface with anti-icing properties engineered using a top-down approach[J]. Applied Surface Science, 2015，351: 920-926.

[48] LIN C C, LIN H J, LIN Y H, et al. Micro/nanostructured surface modification using femtosecond laser pulses on minimally invasive electrosurgical devices[J]. Journal of
Biomedical Materials Research Part B : Applied Biomaterials, 2017, 105(4): 865-873.

[49] HSIAO W T, LIN L H, CHIANG H J, et al. Biomedical electrosurgery devices containing nanostructure for minimally invasive surgery: Reduction of thermal injury and acceleration of wound healing for liver cancer[J]. Journal of Materials Science: Materials in Medicine, 2015, 26(2): 77.

[50] PARK J Y, TENJIMBAYASHI M, MUTO J, et al. Antiadhesion function between a biological surface and a metallic device interface at high temperature by wettability control[J]. ACS Biomaterials Science \& Engineering, 2018, 4(5): 1891-1899.

[51] ZHANG P F, CHEN H W, ZHANG L W, et al Anti-adhesion effects of liquid-infused textured surfaces on high-temperature stainless steel for soft tissue[J]. Applied Surface Science, 2016, 385: 249-256.

作者简介: 陆龙生, 男, 1981 年出生, 博士, 教授, 博士研究生导师。 主要研究方向为表面微纳功能结构制造。

E-mail: meluls@scut.edu.cn

李凯凯, 男, 1996 年出生, 硕士研究生。主要研究方向为表面功能结构 制造。

E-mail: likaikai.scut@gmail.com

谢颖熙(通信作者), 男, 1989 年出生, 博士, 副教授。主要研究方向为 先进表面功能结构制造、先进电子器件制造、先进纳米材料制造等。

E-mail: xieyingxi@scut.edu.cn

万珍平, 男, 1971 年出生, 博士, 教授, 博士研究生导师。主要研究方 向为现代加工理论与技术、表面功能结构制造。

E-mail: zhpwan@scut.edu.cn

丁焕文, 男, 1965 出生, 博士, 教授, 主任医师。主要研究方向为数字 化骨科修复技术、3D 打印医疗器械研究。

E-mail: dhuanwen123@aliyun.com

张志辉, 男, 1976 年出生, 博士, 教授, 博士研究生导师。主要研究方 向为工程仿生、金属复合材料制备与应用研究。

E-mail: zhzh@jlu.edu.cn

汤勇, 男, 1962 年出生, 博士, 教授, 博士研究生导师。主要研究方向 为微制造、表面功能结构制造。

E-mail: ytang@scut.edu.cn 